\title{
Successful lung volume reduction surgery in combined pulmonary emphysema and fibrosis without body-plethysmographic hyperinflation - a case report
}

\author{
Gilles Straub $^{1}$, Claudio Caviezel ${ }^{2}$, Thomas Frauenfelder ${ }^{3}$, Konrad E. Bloch ${ }^{1 \#}$, Daniel Franzen ${ }^{1 \#}$ \\ ${ }^{1}$ Department of Pulmonology, ${ }^{2}$ Department of Thoracic Surgery, ${ }^{3}$ Institute of Diagnostic and Interventional Radiology, University Hospital Zurich, \\ 8091 Zurich, Switzerland \\ \#These authors contributed equally to this work. \\ Correspondence to: Dr. Daniel Franzen, MD. Department of Pulmonology, University Hospital Zurich, Raemistrasse 100, 8091 Zurich, Switzerland. \\ Email: daniel.franzen@usz.ch.
}

\begin{abstract}
Surgical and bronchoscopic lung volume reduction (LVR) have been demonstrated to improve lung function, dyspnea and quality of life in patients with severe pulmonary emphysema. The most important functional prerequisite for a successful LVR is hyperinflation measured by body plethysmography. A residual volume (RV) of more than $180 \%$ predicted and a RV/total lung capacity (TLC) ratio of more than 0.58 were inclusion criteria in major LVR trials. Here we report a successful LVR in a 68-year-old man with advanced, heterogeneous emphysema without plethysmographic evidence of severe hyperinflation (RV/TLC 0.45). Computed tomography (CT) revealed severe, partly bullous upper lobe emphysema and subtle fibrotic changes with volume loss of lower lobes. Since lower lobes appeared compressed by upper lobe emphysema, these target areas were removed by thoracoscopic LVR. Four months later, the patient reported major improvements of dyspnea, $\mathrm{FEV}_{1}$ (by $1.27 \mathrm{~L}$ ) and 6-minute walking distance (by 150 meters). LVR reduced total lung volume measured by CT-volumetry by $0.5 \mathrm{~L}$ and upper lobe volume by $1.85 \mathrm{~L}$ while lower lobe volume increased by $+1.34 \mathrm{~L}$. Low density volume $(-950 \mathrm{HU})$ reflecting emphysema was reduced by $1.73 \mathrm{~L}$. We conclude that the opposing effects of emphysema and fibrosis resulted in a barely increase in total lung volume that was only slightly reduced by LVR. Nevertheless, resection of emphysematous target areas identified by quantitative CT analysis provided major clinical and physiologic improvements related to decompression of low-compliance lower lobe areas retracted by early fibrosis. Therefore, in the combined presence of severe, heterogeneously distributed emphysema and fibrosis, LVR may improve respiratory mechanics even if RV/TLC, an established body-plethysmographic predictor of LVR success is not severely elevated.
\end{abstract}

Keywords: Lung volume reduction surgery (LVRS); emphysema; pulmonary fibrosis; hyperinflation

Submitted Apr 18, 2018. Accepted for publication Jun 12, 2018.

doi: $10.21037 /$ jtd.2018.06.60

View this article at: http://dx.doi.org/10.21037/jtd.2018.06.60

\section{Introduction}

Chronic obstructive lung disease (COPD) is an irreversibly progressive disease with gradual decline of quality of life due to impaired physical performance. The World Health Organization expects the burden of COPD to increase in the next few years due to aging of the world population and to become the $4^{\text {th }}$ leading cause of death in 2030 (1).
The main causes for COPD are smoking and air pollution. Smoking cessation and oxygen therapy in hypoxemic patients are the only known conservative means to prolong life in affected patients. Inhaled medications and pulmonary rehabilitation can increase quality of life and reduce the rate of exacerbations. Hypercapnic patients may benefit from non-invasive ventilation (2). 
Table 1 Pulmonary function before and after lung volume reduction surgery

\begin{tabular}{|c|c|c|c|c|c|c|c|c|}
\hline Time & $\begin{array}{c}\text { FVC (liters) } \\
\text { [\%predicted] }\end{array}$ & $\begin{array}{c}\text { FEV }_{1} \text { (liters) } \\
\text { [\%predicted] }\end{array}$ & $\mathrm{FEV}_{1} / \mathrm{FVC}$ & $\begin{array}{l}\text { TLC (liters) } \\
\text { [\%predicted] }\end{array}$ & $\begin{array}{c}\text { RV (liters) } \\
\text { [\%predicted] }\end{array}$ & $\mathrm{RV} / \mathrm{TLC}$ & $\begin{array}{c}\text { TLCO } \\
\text { [\%predicted] }\end{array}$ & $\begin{array}{l}\text { 6-MWD } \\
\text { (meters) }\end{array}$ \\
\hline Before LVRS & 2.94 [80] & 1.19 [42] & 0.40 & 7.95 [122] & $3.61[145]$ & 0.45 & 30 & 450 \\
\hline \multicolumn{9}{|l|}{ After LVRS } \\
\hline 5 months po & 5.16 [136] & $2.46[84]$ & 0.47 & 7.97 [120] & 2.48 [98] & 0.31 & 36 & 600 \\
\hline 24 months po & $4.75[121]$ & 1.98 [67] & 0.42 & - & - & - & 34 & - \\
\hline
\end{tabular}

$\mathrm{FEV}_{1}$, forced expiratory volume in one second; FVC, forced vital capacity; LVRS, lung volume reduction surgery; po, postoperative; RV, residual volume; TLC, total lung capacity; TLCO, transfer factor of the lung for carbon monoxide; 6-MWD, 6-minute walking distance.

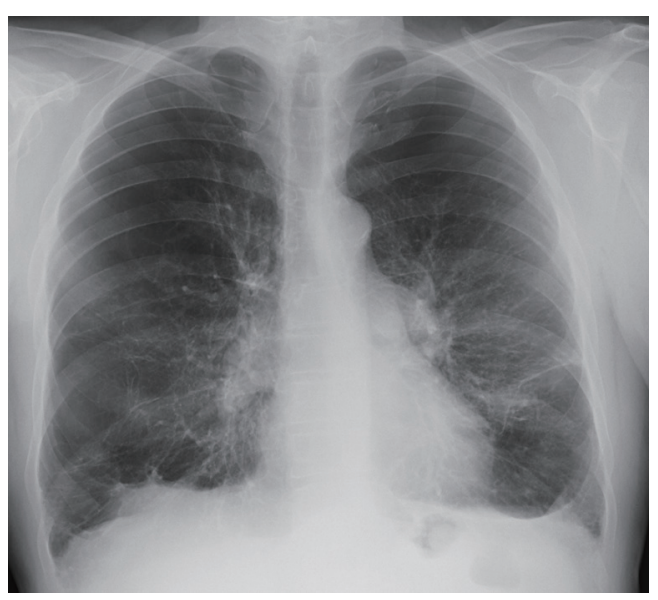

Figure 1 Preoperative chest X-ray.

Lung volume reduction (LVR) - both surgical or bronchoscopic—showed a benefit in quality of life and survival in multiple randomized trials in selected patients with severe airflow obstruction and hyperinflation (3-8). Usually, static hyperinflation is assessed with body plethysmography based on residual volume (RV) and RV/ total lung capacity (TLC) ratio (9). RV of more than $175 \%$ predicted and a RV/TLC ratio of more than 0.58 were main inclusion criteria in major studies (3-6,10-17). Both parameters are key features to qualify for a $\operatorname{LVR}(18,19)$, since the diaphragm has been demonstrated to gain strength after "deflation" of the lung (20).

To the best of our knowledge, this is the first report on a successful surgical LVR in an emphysema patient without the conventional evidence of hyperinflation measured by body plethysmography.

\section{Case presentation}

A 68-year-old patient was referred for evaluation of a LVR therapy. He was on inhaled bronchodilators [long-acting beta 2 -agonist (LABA), long-acting muscarinic antagonist (LAMA)] and topical glucocorticoids, had participated in several pulmonary rehabilitation programs and was on long term oxygen therapy. Despite of all the therapies he still suffered from severe dyspnea on minimal exertion (e.g., after climbing more than one fleet of stairs), while he denied chronic cough and acute exacerbations. Due to his severely impaired exercise tolerance, he already mentioned early signs of social retreat and depression. At physical examination, the patient had a marked barrellike configuration of his thorax with slightly elevated shoulders suggesting clinical evidence of hyperinflation and pursed lip breathing during. Spirometry revealed severe airflow obstruction with an $\mathrm{FEV}_{1}$ of $42 \%$ predicted, and TLC and RV measured by body plethysmography were $122 \%$ predicted and $145 \%$ predicted, respectively (Table 1). Based on TLC, RV and the ratio of RV/TLC of 0.45 , there was no evidence of severe absolute or relative hyperinflation. The chest radiograph revealed signs of mild hyperinflation, an increased transparency of upper lobes and reticular changes in the lower lobes (Figure 1). Chest computed tomography (CT) showed a pronounced heterogeneity of the lung density. In particular, the right upper and middle lobes, and, to a lesser extent, also the left upper lobe, revealed partially bullous emphysematous destruction of the lung architecture, while the lower lobes were of much higher density suggesting some compression and early fibrotic changes in some areas (Figure 2). CT volumetry revealed a total lung volume of $8.01 \mathrm{~L}$, 

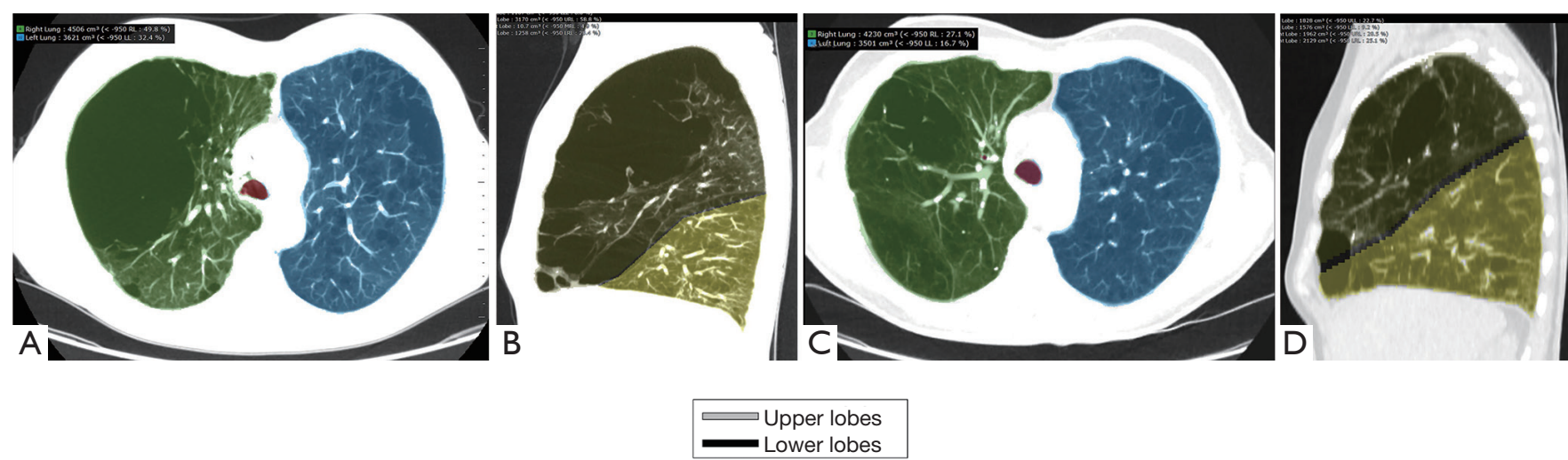

CT-volumetric lung volumes
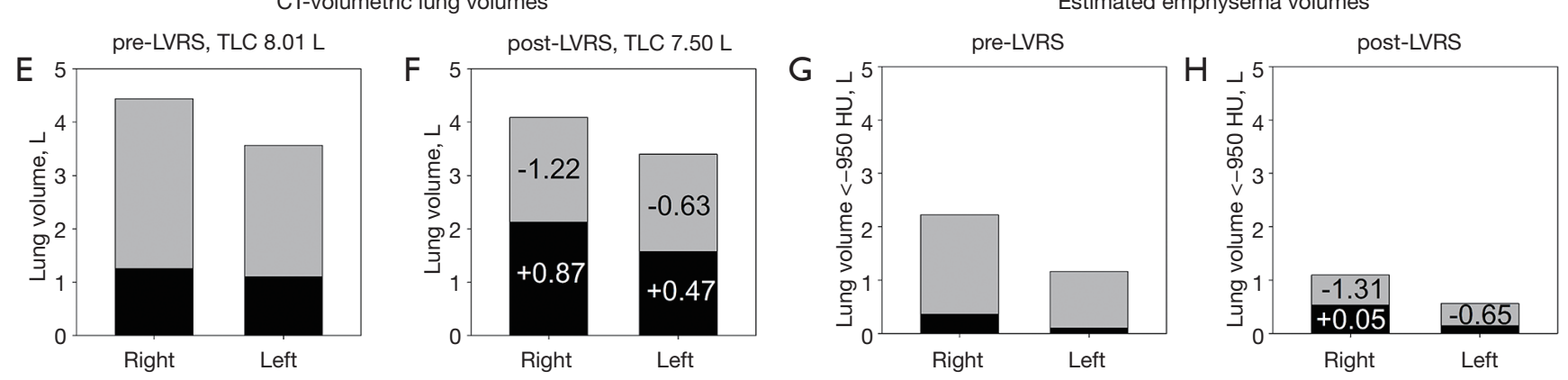

Figure 2 Quantitative CT analysis. (A-D) show representative transverse and sagittal CT sections before (A,B) and 5 months after LVR (C,D). Bullous emphysematous changes are appreciated in the upper lobes while the lower lobes have an increased density and linear opacities. These alterations are pronounced before LVR and reduced after the intervention. $(\mathrm{E}-\mathrm{H})$ show the CT-volumetrically determined volumes of the upper and lower lobes before and after LVR (E,F) and the lung volume with very low density (-950 HU) considered to represent emphysema $(\mathrm{G}, \mathrm{H})$. LVR decreased upper lobe and increased lower lobe volumes by the amount indicated in the columns (values in liters). The decrease in the left and right lung volume ( $\mathrm{F},-1.85$ liters) is nearly identical to the decrease in tissue of very low density (H, -1.96 liters) suggesting that virtually all resected volume was of very low density (emphysema). LVRS, lung volume reduction surgery.

which was very similar to the TLC of $7.95 \mathrm{~L}$ measured by body plethysmography (Figure 2, Table 1). According to CT-volumetry, the volume of both upper lobes was $5.63 \mathrm{~L}$, the volume of the middle and lower lobes, $3.38 \mathrm{~L}$. The estimated emphysema volume based on lung zones with very low density below $-950 \mathrm{HU}$ was $3.38 \mathrm{~L}$.

After interdisciplinary discussion with thoracic surgeons the decision was made to offer surgical LVR because of the obvious CT-radiological signs of regional hyperinflation and bullous lung destruction in combination with basal fibrosis. The patient was informed about the missing conventional inclusion criteria. Nevertheless, he fully agreed to undergo the procedure despite possible disadvantages or complications.

Thoracoscopic LVR of the most destructed areas of the right upper and middle lobes and of the left upper lobe was performed. There were no perioperative complications. Drainage time was 3 days. Only a few days after the operation the patient already perceived an improvement of dyspnea, and he could be dismissed from hospital on the 4th postoperative day. Five months later, the patient was in markedly improved physical and psychological condition. His pulmonary function showed a marked increase in $\mathrm{FEV}_{1}$ by $107 \%(+1.27 \mathrm{~L})$, no significant change in TLC (by body plethysmography), a decrease in RV by $1.13 \mathrm{~L}$, and the 6-minute walking distance (6-MWD) improved by 150 meters (Table 1). Successful LVR was confirmed by quantitative CT analysis (Figure 2) suggesting a major reduction in upper lobe volume corresponding to areas destructed by emphysema, and a simultaneous increase in lower lobe volume. Lung function and 6-MWD gradually declined over the next 2 years, and the patient developed 
progressive combined pulmonary fibrosis and emphysema (CPFE) with pulmonary artery hypertension [mean pulmonary artery pressure (mPAP) $59 \mathrm{mmHg}$.

\section{Discussion}

In severe pulmonary emphysema hyperinflation is assessed routinely by body plethysmography. Increased RV and RV/TLC are established predictors of successful LVR, independent of whether by surgery or by bronchoscopy (18). According to the described case, there might be a selected number of patients who benefit from LVR even though RV and RV/TLC, which are global measures of hyperinflation, are only moderately increased. In some of these highly selected patients pronounced regional hyperinflation evidenced by CT in combination with less affected areas or even areas with reduced lung compliance such as in pulmonary fibrosis may suggest the potential for a benefit from targeted LVR. An appealing explanation of the lack of plethysmographic evidence of significant hyperinflation in the described case is that total lung volume measured globally by plethysmography was only slightly elevated. Evidently, the pronounced hyperinflation of upper lobes and apical lower lobes was offset by volume loss in the lower lobes due compression and retraction by fibrosis. CT before LVR showed slight reticular opacities of both basal lung fields. Consistently, airflow obstruction and hyperinflation have been demonstrated to be counteracted by pulmonary fibrosis in cases of CPFE (21).

According to the CT-volumetric and densitometric analysis, the LVR reduced the total lung volume only mildly (by $0.5 \mathrm{~L}$ ) but it confirmed removal of $1.85 \mathrm{~L}$ of upper lobe volume and reduction of emphysematous tissue by $1.96 \mathrm{~L}$ (Figure 2). This suggests that the surgeon was able to remove nearly exclusively emphysematous target areas. At the same time, the lower lobe volume increased significantly by $1.34 \mathrm{~L}$ (Figure 2) with virtually no increase in the very low density volume. This is consistent with no change in the amount of emphysema in the lower lobes that were rather dense due to early fibrosis. Therefore, LVR seemed to have reduced compression of the lower lobes that were subsequently expanded to a greater extent which may have contributed to improvement of airflow obstruction as suggested by an increase in $\mathrm{FEV}_{1}$ and $\mathrm{FEV}_{1} / \mathrm{FVC}$.

There is increasing evidence of the clinical importance of dynamic hyperinflation in patients with COPD (22). Dynamic hyperinflation might also explain the exercise limitation in the current patient before LVR. Expiratory collapse of the airways in areas of the lung with emphysematous destruction together with a reduced airway calibre due to progressive compression of the lower lobes due to increasing hyperinflation of the upper lobes during physical exertion might have exacerbated airflow obstruction. However, we could not verify this hypothesis in our patient because CT-volumetry during exercise is not feasible and repeated inspiratory capacity measurements that are performed to evaluate global dynamic hyperinflation would not have detected the relative volume changes in the upper and lower lobes.

\section{Conclusions}

Our observations demonstrate that in selected (rare) cases, LVR may provide a clinical and functional improvement in patients with emphysema even when established predictors of successful LVR such as elevations in TLC, RV and RV/ TLC are not pronounced. Quantitative CT analysis may identify regional hyperinflation due to emphysema in combination with reduced volume of lung regions with fibrotic changes such as in patients with CPFE that result in mutually opposing changes of lung volume. LVR of carefully targeted emphysematous areas of the lung may provide clinical and functional improvement in these particular conditions.

\section{Acknowledgements}

None.

\section{Footnote}

Conflicts of Interest: The authors have no conflicts of interest to declare.

Informed Consent: Written informed consent was obtained from the patient for publication of this manuscript and any accompanying images.

\section{References}

1. Mathers CD, Loncar D. Projections of global mortality and burden of disease from 2002 to 2030. PLoS Med 2006; 3:e442.

2. Osadnik CR, Tee VS, Carson-Chahhoud KV, et al. Non-invasive ventilation for the management of acute hypercapnic respiratory failure due to exacerbation of chronic obstructive pulmonary disease. Cochrane Database 
Syst Rev 2017;7:CD004104.

3. Kemp SV, Slebos DJ, Kirk A, et al. A Multicenter Randomized Controlled Trial of Zephyr Endobronchial Valve Treatment in Heterogeneous Emphysema (TRANSFORM). Am J Respir Crit Care Med 2017;196:1535-43.

4. Valipour A, Slebos DJ, Herth F, et al. Endobronchial Valve Therapy in Patients with Homogeneous Emphysema. Results from the IMPACT Study. Am J Respir Crit Care Med 2016;194:1073-82.

5. Sciurba FC, Criner GJ, Strange C, et al. Effect of Endobronchial Coils vs Usual Care on Exercise Tolerance in Patients With Severe Emphysema: The RENEW Randomized Clinical Trial. JAMA 2016;315:2178-89.

6. Fishman A, Martinez F, Naunheim K, et al. A randomized trial comparing lung-volume-reduction surgery with medical therapy for severe emphysema. N Engl J Med 2003;348:2059-73.

7. Weder W, Tutic M, Lardinois D, et al. Persistent benefit from lung volume reduction surgery in patients with homogeneous emphysema. Ann Thorac Surg 2009;87:22936; discussion 236-7.

8. Garner J, Kemp SV, Toma TP, et al. Survival after Endobronchial Valve Placement for Emphysema: A 10-Year Follow-up Study. Am J Respir Crit Care Med 2016;194:519-21.

9. Stocks J, Godfrey S, Beardsmore C, et al. Plethysmographic measurements of lung volume and airway resistance. ERS/ATS Task Force on Standards for Infant Respiratory Function Testing. European Respiratory Society/ American Thoracic Society. Eur Respir J 2001;17:302-12.

10. Layton AM, Armstrong HF, Moran SL, et al. Quantification of Improvements in Static and Dynamic Ventilatory Measures Following Lung Volume Reduction Surgery for Severe COPD. Chronic Obstr Pulm Dis 2015;2:61-9.

11. Davey C, Zoumot Z, Jordan S, et al. Bronchoscopic lung volume reduction with endobronchial valves for patients with heterogeneous emphysema and intact interlobar fissures (the BeLieVeR-HIFi study): a randomised controlled trial. Lancet 2015;386:1066-73.

12. Klooster K, Hartman JE, Ten Hacken NH, et al. One-Year Follow-Up after Endobronchial Valve Treatment in Patients with Emphysema without Collateral Ventilation Treated in the STELVIO Trial. Respiration 2017;93:112-21.

13. Herth FJ, Noppen M, Valipour A, et al. Efficacy predictors of lung volume reduction with Zephyr valves in a European cohort. Eur Respir J 2012;39:1334-42.

14. Sciurba FC, Ernst A, Herth FJ, et al. A randomized study of endobronchial valves for advanced emphysema. N Engl J Med 2010;363:1233-44.

15. Deslee G, Mal H, Dutau H, et al. Lung Volume Reduction Coil Treatment vs Usual Care in Patients With Severe Emphysema: The REVOLENS Randomized Clinical Trial. JAMA 2016;315:175-84.

16. Herth FJ, Valipour A, Shah PL, et al. Segmental volume reduction using thermal vapour ablation in patients with severe emphysema: 6-month results of the multicentre, parallel-group, open-label, randomised controlled STEPUP trial. Lancet Respir Med 2016;4:185-93.

17. Thurnheer R, Engel H, Weder W, et al. Role of lung perfusion scintigraphy in relation to chest computed tomography and pulmonary function in the evaluation of candidates for lung volume reduction surgery. Am J Respir Crit Care Med 1999;159:301-10.

18. Herth FJF, Slebos DJ, Criner GJ, et al. Endoscopic Lung Volume Reduction: An Expert Panel Recommendation Update 2017. Respiration 2017;94:380-8.

19. Fessler HE, Permutt S. Lung volume reduction surgery and airflow limitation. Am J Respir Crit Care Med 1998;157:715-22.

20. Criner G, Cordova FC, Leyenson V, et al. Effect of lung volume reduction surgery on diaphragm strength. Am J Respir Crit Care Med 1998;157:1578-85.

21. Zhang L, Zhang C, Dong F, et al. Combined pulmonary fibrosis and emphysema: a retrospective analysis of clinical characteristics, treatment and prognosis. BMC Pulm Med 2016;16:137.

22. Silva CS, Nogueira FR, Porto EF, et al. Dynamic hyperinflation during activities of daily living in COPD patients. Chron Respir Dis 2015;12:189-96.

Cite this article as: Straub G, Caviezel C, Frauenfelder T, Bloch KE, Franzen D. Successful lung volume reduction surgery in combined pulmonary emphysema and fibrosis without body-plethysmographic hyperinflation-a case report. J Thorac Dis 2018;10(Suppl 23):S2830-S2834. doi: 10.21037/ jtd.2018.06.60 